\title{
A methodology for the simulation of digital-to-analog converters
}

Linhui Liu, Wei Li

Linhui Liu, Wei Li, "A methodology for the simulation of digital-to-analog converters," Proc. SPIE 7490, PIAGENG 2009: Intelligent Information, Control, and Communication Technology for Agricultural Engineering, $74901 \mathrm{Z}$ (10 July 2009); doi: 10.1117/12.836788

SPIE Event: International Conference on Photonics and Image in Agriculture Engineering (PIAGENG 2009), 2009, Zhangjiajie, China 


\section{A methodology for the simulation of digital-to-analog converters (Withdrawal Notice)}

Proc. SPIE 7490, $74901 Z$ (2009); http://dx.doi.org/10.1117/12.836788

Online Publication Date: 10 July 2009

Withdrawn from Publication: 13 November 2015

Conference Date: 11-12 July 2009

Conference Location: Zhangjiajie, China

Conference Title: PIAGENG 2009: Intelligent Information, Control, and Communication Technology for Agricultural Engineering

Conference Chairs: Honghua Tan, Qi Luo

\section{Linhui Liu}

Changsha Univ. of Science and Technology (China)

\section{Wei Li}

Hunan Univ. (China)

This paper has been identified by SPIE as fraudulent and was withdrawn on 13 November 2015.

PIAGENG 2009: Intelligent Information, Control, and Communication Technology 